\title{
Acute and neuropathic orofacial antinociceptive effect of eucalyptol
}

\author{
José de Maria de Albuquerque de Melo Júnior ${ }^{1} \cdot$ Marina de Barros Mamede Vidal Damasceno $^{1}$. \\ Sacha Aubrey Alves Rodrigues Santos ${ }^{1}$. Talita Matias Barbosa ${ }^{1,2} \cdot$ João Ronielly Campêlo Araújo ${ }^{1,3}$. \\ Antonio Eufrásio Vieira-Neto ${ }^{1,3} \cdot$ Deysi Viviana Tenazoa Wong ${ }^{2}$. Roberto César Pereira Lima-Júnior ${ }^{2}$. \\ Adriana Rolim Campos ${ }^{1}(\mathbb{D})$
}

Received: 23 December 2016/Accepted: 2 February 2017/Published online: 16 February 2017

(C) Springer International Publishing 2017

\begin{abstract}
Terpenes have a wide range of pharmacological properties, including antinociceptive action. The anti-inflammatory and antinociceptive effects of eucalyptol are well established. The purpose of this study was to evaluate the antinociceptive effect of eucalyptol on acute and neuropathic orofacial pain in rodent models. Acute orofacial and corneal nociception was induced with formalin, capsaicin, glutamate and hypertonic saline in mice. In another series, animals were pretreated with capsazepine or ruthenium red to evaluate the involvement of TRPV1 receptors in the effect of eucalyptol. In a separate experiment, perinasal tissue levels of IL- $1 \beta$, TNF- $\alpha$ and IFN- $\gamma$ were measured. Rats were pretreated with eucalyptol before induction of temporomandibular joint pain with formalin or mustard oil. In another experiment, rats were submitted to infraorbital nerve transection (IONX) to induce chronic pain, followed by induction of mechanical hypersensitivity using Von Frey hairs. Locomotor performance was evaluated with the open-field test, and molecular docking was conducted on the TRPV1 channel. Pretreatment with eucalyptol significantly reduced formalin-induced nociceptive behaviors in all mouse strains, but response was more homogenous in the Swiss strain. Eucalyptol produced antinociceptive effects in all tests. The effect was sensitive
\end{abstract}

Adriana Rolim Campos

adrirolim@unifor.br

1 Experimental Biology Center (NUBEX), University of Fortaleza (UNIFOR), Av. Washington Soares 1321, Edson Queiroz, Fortaleza, Ceará CEP 60811-905, Brazil

2 Department of Physiology and Pharmacology, Federal University of Ceará (UFC), Fortaleza, Ceará, Brazil

3 Department of Biochemistry and Molecular Biology, Federal University of Ceará (UFC), Fortaleza, Ceará, Brazil to capsazepine but not to ruthenium red. Moreover, eucalyptol significantly reduced IFN- $\gamma$ levels. Matching the results of the experiment in vivo, the docking study indicated an interaction between eucalyptol and TRPV1. No locomotor activity changes were observed. Our study shows that eucalyptol may be a clinically relevant aid in the treatment of orofacial pain, possibly by acting as a TRPV1 channel antagonist.

Keywords Eucalyptol - Orofacial nociception - IFN- $\gamma$. TRPV1

\section{Introduction}

Several pharmacological studies have documented the anticancer, antimicrobial, antifungal, antiviral, antihyperglycemic, analgesic, anti-inflammatory and antiparasitic properties of terpenes (Guimarães et al. 2014). The monoterpenoids menthol (Anderson et al. 2014), citronellol (Brito et al. 2013), carvacrol (Guimarães et al. 2012) and citronellal (Quintans-Júnior et al. 2010) have specific orofacial antinociceptive effects.

Eucalyptol, a natural monoterpenoid, is the main active component of several essential oils, especially the essential oil extracted from the Tasmanian bluegum (Eucalyptus globulus). Its therapeutic role in inflammatory respiratory diseases, such as asthma and chronic obstructive pulmonary disease (COPD), is well established. The effect is associated with the anti-inflammatory (Kim et al. 2015) and antioxidant (Rocha Caldas et al. 2015) properties of eucalyptol, as shown by a number of preclinical studies. Another recent clinical study demonstrated the long-term benefits of treatment with eucalyptol in COPD prevention and asthma control (Juergens 2014). 
Regarding the toxicity of eucalyptol, Caldas et al. (2016) recently estimated the LD50 between 1.500 and $1.750 \mathrm{mg} /$ $\mathrm{kg}$ in mice. They also provided evidence that possibly eucalyptol presents maternal and fetal toxicity and the need of more detailed investigation to better characterize the toxic effects of this monoterpene.

Although experimental studies have confirmed the antinociceptive properties of eucalyptol (Santos and Rao 2000; de Sousa et al. 2004; Liapi et al. 2007), to our knowledge no previous study has evaluated the effect of eucalyptol on orofacial pain. To fill this gap, in the present study we evaluated the antinociceptive effect of eucalyptol on acute and neuropathic orofacial pain in rodent models.

\section{Experimental section}

\section{Animals}

C57BL/6 J, BALB/c and Swiss albino mice (20-25 g) and Wistar rats (250-300 g) from the experimental animal facility of the University of Fortaleza (UNIFOR) were used in this study. The animals were kept in a controlled environment (circadian cycle, $22{ }^{\circ} \mathrm{C}$ ) with free access to water and standard pellet diet (Purina, São Paulo, Brazil). The experimental protocols followed the ethical guidelines of CONCEA (Brazilian Council for the Control of Animal Experimentation) and were approved by the UNIFOR Animal Research Ethics Committee under entry number 009/2015 on 16 December 2015.

\section{Obtention of eucalyptol}

Eucalyptol (99\% purity) was purchased from SigmaAldrich $^{\circledR}$.

\section{Formalin-induced nociception}

Orofacial nociception was induced in mice (Swiss, C57BL/ $6 \mathrm{~J}$ or BALB/c) by injection of $1 \%$ formalin $(20 \mu \mathrm{L}$, s.c) in the right upper lip (perinasal area) using a 27 -gauge needle. Nociception was quantified as time (s) spent rubbing the site of injection with the fore- or hindpaw 0-5 min (phase 1) and 15-20 min (phase 2) after induction. To assess the effect of the test drug, mice ( $n=6 /$ group) were pretreated per oros with vehicle at $10 \mathrm{~mL} / \mathrm{Kg}$ (control) or eucalyptol at 100,200 or $400 \mathrm{mg} / \mathrm{Kg} 60 \mathrm{~min}$ before induction.

To verify the possible involvement of the TRPV1 channel in the effect of eucalyptol, Swiss mice ( $n=6$ /group) were pretreated with the competitive antagonist capsazepine $(5 \mathrm{mg} / \mathrm{Kg}$; s.c.) or the noncompetitive antagonist ruthenhium red $(3 \mathrm{mg} / \mathrm{Kg}$; s.c.) $15 \mathrm{~min}$ before administration of eucalyptol $(200 \mathrm{mg} / \mathrm{Kg})$.
In another set of experiments, after the evaluation of the formalin-induced orofacial nociception, perinasal tissue levels of the cytokines IL- $1 \beta$, TNF- $\alpha$ and IFN- $\gamma$ were measured. The assays were carried out using a commercial colorimetric ELISA kit (Duo-set, R\&D System), following the manufacturer's recommendations. A naive group was included.

\section{Capsaicin-induced nociception}

Swiss mice ( $n=6$ /group) were injected with capsaicin (20 $\mu \mathrm{L}, 2.5 \mu \mathrm{g}$ ) in the right upper lip (perinasal area) using a 27-gauge needle. Nociception was quantified as time(s) spent rubbing the site of injection with the fore- or hindpaw 10-20 min after induction. Eucalyptol and vehicle were administered in a similar manner and at the same doses as in the previous test.

\section{Glutamate-induced nociception}

Swiss mice ( $n=6$ /group) were injected with glutamate (20 $\mu \mathrm{L}, 25 \mathrm{mmol}$ ) in the right upper lip (perinasal area) using a 27-gauge needle. Nociception was quantified as time(s) spent rubbing the site of injection with the fore- or hindpaw $15 \mathrm{~min}$ after induction. Eucalyptol and vehicle were administered in a similar manner and at the same doses as in the previous test.

\section{Eye-wiping test}

Corneal nociception was induced in mice by instillation of one drop $(20 \mu \mathrm{L})$ of hypertonic saline $(5 \mathrm{M} \mathrm{NaCl})$ on the corneal surface using a fine dropper. The number of eye wipes performed with the ipsilateral forepaw during the first $30 \mathrm{~s}$ was registered. Swiss mice ( $n=6$ /group) were pretreated p.o. with $0.9 \%$ saline $(0.15 \mathrm{M} \mathrm{NaCl}$; control) or eucalyptol at 100,200 or $400 \mathrm{mg} / \mathrm{kg} 60 \mathrm{~min}$ before induction.

\section{Temporomandibular joint formalin or mustard oil test}

Rats ( $n=6 /$ group) were acclimated individually in a glass test chamber $(30 \times 30 \times 30 \mathrm{~cm})$ for $30 \mathrm{~min}$ to minimize stress. The groups were pretreated with eucalyptol ( $200 \mathrm{mg} / \mathrm{Kg}$, p.o.). Sixty minutes later, the left temporomandibular joint (TMJ) was injected with $50 \mu \mathrm{L} 1.5 \%$ formalin or $2.5 \%$ mustard oil using a Hamilton syringe and a 30-gauge needle. A sham group $(0.9 \% \mathrm{NaCl})$ was included.

Following induction and recovery from anesthesia, the animals were returned individually to the test chamber to quantify nociception: asymmetrical rubbing of the 
orofacial region with the ipsilateral fore- or hindpaw, and head flinching (intermittent and reflexive shaking of the head). Using a chronometer, the time (s) spent rubbing the orofacial region was registered 12 times at 3-min intervals. Head flinching was registered as absence/presence.

\section{Assessment of mechanical sensitivity following infraorbital nerve transection}

Rats were submitted to anesthesia with ketamine (100 mg/ $\mathrm{Kg})$ and xylazine $(10 \mathrm{mg} / \mathrm{Kg})$ i.p. in order to expose the left infraorbital nerve (ION) at its entry into the infraorbital foramen by way of an intraoral incision $(2 \mathrm{~mm})$ in the oral mucosa of the left fronto-lateral maxillary vestibulum. The ION was lifted from the maxillary bone and cut (IONX) without damaging adjacent nerves and vessels. Subsequently, the animals were returned to their cages and fed with mash and chow. The animals were monitored daily in the postoperative period.

The rats were acclimated, trained and tested for facial mechanical sensitivity one day prior to nerve transection (baseline) and on postoperative days 1, 3, 5, 7, 10, 14 and 21. A single dose of eucalyptol $(200 \mathrm{mg} / \mathrm{Kg})$ or saline $(10 \mathrm{~mL} / \mathrm{kg})$ was administered per oros $60 \mathrm{~min}$ before each postoperative test. Naïve and sham-operated animals were used as controls. Mechanical sensitivity of the whisker pad skin was assessed by the use of Von Frey hairs. The headwithdrawal threshold to mechanical stimulation of the whisker pad skin was defined as the minimum pressure needed to evoke an escape more than 3 times of 5 stimuli. All the groups in the experiment included 6 animals.

\section{Locomotor activity (open-field test)}

The open-field area was made of acrylic (transparent walls and black floor) divided into nine squares of equal size. Swiss mice ( $n=6 /$ group) were treated with vehicle $(10 \mathrm{~mL} / \mathrm{kg}$, p.o.) or eucalyptol $(200 \mathrm{mg} / \mathrm{kg}$, p.o.). The number of squares crossed with all four paws was registered during a 5-min period.

\section{Molecular docking study}

The interaction between eucalyptol and the pain receptor TRPV1 was analyzed using molecular docking. The structures of eucalyptol and TRPV1 were retrieved from the Pubchem and Protein Data Bank (codes 2758 and 3J5P, respectively). The software HEX 8.0.0 was used for molecular docking calculations. The parameters used in the docking process were: correlation typēshape only; calculation devicēCPU; FFT mode 3D fast life; grid dimensioñ 0.6; receptor range 180; ligand range 180; twist range 360; and distance range 40 . The direct action of eucalyptol on TRPV1 amino acids was viewed using PyMOL v1.4.7.

\section{Statistical analysis}

The results are presented as mean \pm S.E.M. of each group of 6 animals. The data were submitted to one-way variance analysis (ANOVA) followed by Tukey's or Bonferronís test post hoc for multiple comparisons. The level of statistical significance was set at $5 \%(p<0.05)$.

\section{Results and discussion}

The antinociceptive effects of eucalyptol are well established (Santos and Rao 2000; Liapi et al. 2007) but no previous study has evaluated the ability of eucalyptol to produce orofacial antinociception. In the present study we demonstrate that eucalyptol reduces nociceptive behaviors in experimental models of acute orofacial nociception without affecting locomotor activity.

Swiss mice pretreated with eucalyptol presented lower intensity of formalin-induced face rubbing in both phases of the test. When C57BL/6J mice were used, the effect was observed in phase 1 , but not in phase 2 . When BALB/c mice were used, the effect was observed in phase 1 (regardless of dose) and in phase 2 (only at the highest dose: $400 \mathrm{mg} / \mathrm{kg}$ ) (Table 1).

No differences in perinasal tissue IL- $1 \beta$ and TNF- $\alpha$ levels were observed between the control group and the eucalyptol group $(200 \mathrm{mg} / \mathrm{kg})$ after formalin administration. Surprisingly, IFN- $\gamma$ levels were significantly reduced by pretreatment with eucalyptol (Table 3; Fig. 1).

Transient receptor potential (TRP) channels constitute the largest group of transducer molecules involved in nociception in mammals (Sousa-Valente et al. 2014). Eucalyptol is known to activate TRPM8, an essential coldactivated receptor in sensory neurons and, as shown recently, a TRPA1 antagonist (Takaishi et al. 2012).

TRPA1 appears to be the main receptor responsible for the physiological and behavioral responses observed in models of formalin-induced orofacial nociception (McNamara et al. 2007), justifying the choice of eucalyptol for the present study. The observed antinociceptive effect was more evident in Swiss mice than in C57BL/6J or BALB/c mice, making the former a more suitable model for the remainder of the experiments. Mouse genotype plays a role in sensitivity to formalin injected in the paw, as shown by Mogil et al. (1998), but ours is to our knowledge the first study to identify Swiss mice as the most suitable strain for the study of formalin-induced orofacial nociception.

Cytokines may be proinflammatory (released by Th1 cells), such as IL-1 $\beta$, IL-2, IL-6, IL-8, IL-12, IFN- $\gamma$ and 
Table 1 Effect of eucalyptol on formalin-induced orofacial nociception

\begin{tabular}{|c|c|c|c|c|c|c|c|}
\hline \multirow[t]{3}{*}{ Treatment } & \multirow[t]{3}{*}{ Dose $(\mathrm{mg} / \mathrm{Kg})$} & \multicolumn{6}{|l|}{ Face rubbing (s) } \\
\hline & & \multicolumn{3}{|l|}{ Phase 1} & \multicolumn{3}{|l|}{ Phase 2} \\
\hline & & Swiss & C57BL/6J & $\mathrm{BALB} / \mathrm{c}$ & Swiss & C57BL/6J & $\mathrm{BALB} / \mathrm{c}$ \\
\hline Control & - & $81.50 \pm 10.96$ & $124.80 \pm 13.52$ & $52.40 \pm 4.85$ & $38.83 \pm 2.56$ & $19.83 \pm 4.38$ & $56.40 \pm 21.38$ \\
\hline \multirow[t]{3}{*}{ Eucalyptol } & 100 & $32.67 \pm 3.25 * * *$ & $97.17 \pm 4.02$ & $5.80 \pm 1.59 * *$ & $3.17 \pm 0.79 * * * *$ & $20.00 \pm 5.73$ & $10.80 \pm 4.14$ \\
\hline & 200 & $28.50 \pm 4.90 * * * *$ & $46.83 \pm 3.89 * * * *$ & $20.60 \pm 3.94^{*}$ & $7.83 \pm 2.58 * * * *$ & $18.33 \pm 7.92$ & $36.40 \pm 11.06$ \\
\hline & 400 & $14.67 \pm 1.91 * * * *$ & $44.60 \pm 5.85^{* * * *}$ & $5.80 \pm 1.69 * *$ & $6.67 \pm 1.41 * * * *$ & $22.20 \pm 3.54$ & $2.80 \pm 2.31 *$ \\
\hline
\end{tabular}

Results are expressed as mean values \pm SEM in relation to the control group

$* p<0.05$, ** $p<0.01$, *** $p<0.001$ and $* * * * p<0.0001$. ANOVA followed by Tukeýs test
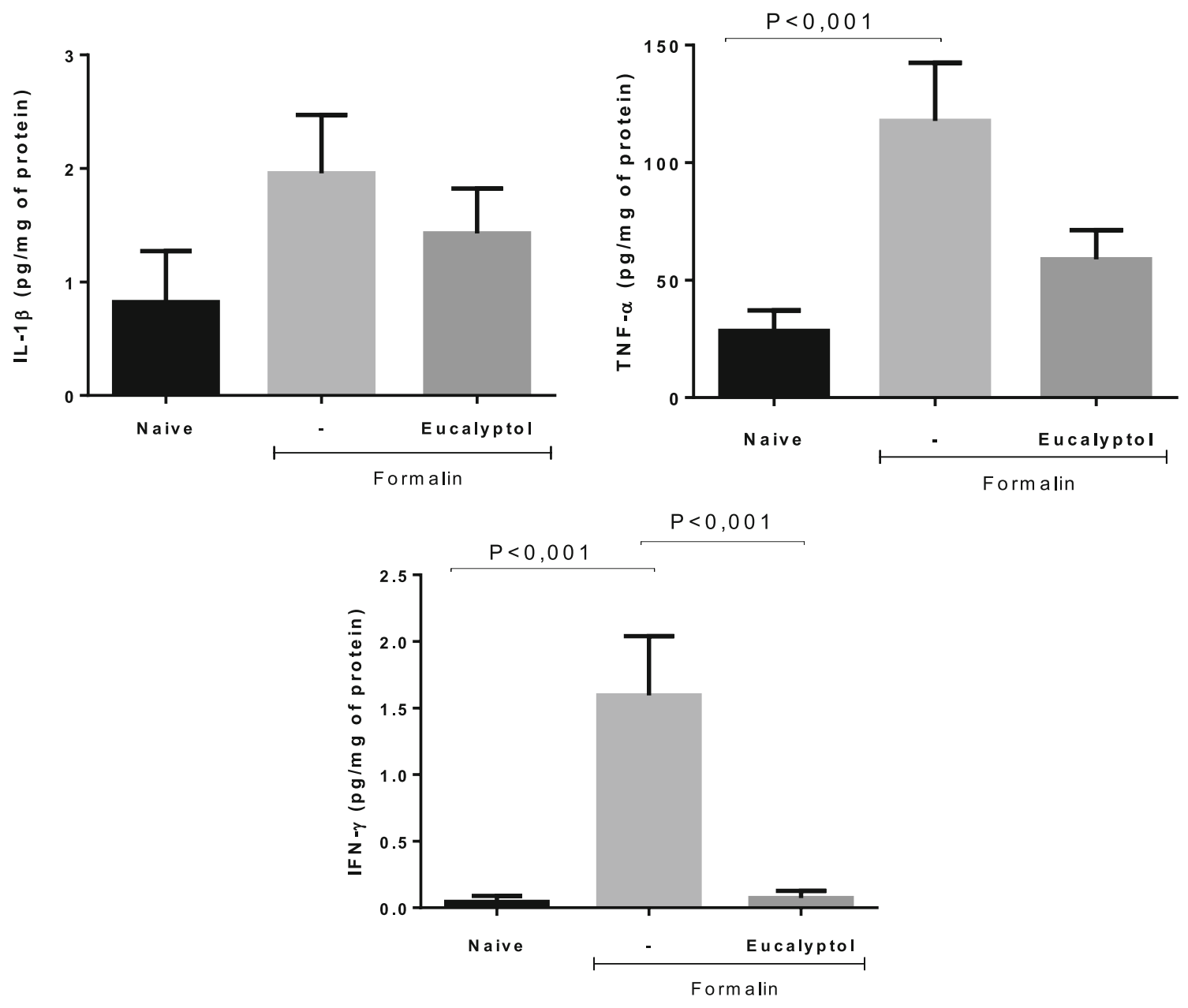

Fig. 1 Effect of eucalyptol (200 mg/kg) on IL-1 $\beta$, TNF- $\alpha$ and IFN- $\gamma$ levels. Results are expressed as mean values \pm S.E.M. ANOVA followed by Bonferroni's test

TNF- $\alpha$, or anti-inflammatory (released by Th2 cells), such as L-4, IL-10, IGF-10, IL-13. Chichorro et al. (2004) demonstrated that peripherally produced TNF- $\alpha$, IL- $1 \beta$, IL6 and IL- 8 are involved in the second phase of formalininduced orofacial nociception.

In this study, high levels of TNF- $\alpha$, IL-1 $\beta$ and IFN- $\gamma$ were detected in the perinasal region of animals injected with formalin. Eucalyptol only prevented the rise in IFN- $\gamma$ levels. In a study by Zhao et al. (2014) using a murine model of lipopolysaccharide-induced acute pulmonary inflammation, eucalyptol played an important role in reducing macrophage infiltration. In the context of our experiment, the stimulation of resident cells (such as macrophages) may be one of the factors regulating 
Table 2 Effect of pretreatment with capsazepine or ruthenium red on eucalyptol-induced orofacial antinociception in mice

\begin{tabular}{llll}
\hline Treatment & Dose $(\mathrm{mg} / \mathrm{Kg})$ & Face rubbing $(\mathrm{s})$ & Phase 2 \\
\cline { 3 - 4 } & & Phase 1 & $48.67 \pm 8.55$ \\
Control & - & $102.80 \pm 12.63$ & $10.50 \pm 3.73^{* *}$ \\
Eucalyptol & 200 & $20.83 \pm 6.29^{* * *}$ & $43.00 \pm 18.54$ \\
Capsazepine & 5 & $62.50 \pm 5.87$ & $66.00 \pm 18.91$ \\
Ruthenium red & 3 & $52.83 \pm 8.53^{*}$ & $69.83 \pm 19.82^{\#}$ \\
Capsazepine + eucalyptol & $5+200$ & $77.50 \pm 18.61^{\#}$ & $19.50 \pm 10.37$ \\
Ruthenium red + eucalyptol & $3+200$ & $45.67 \pm 12.86^{* *}$ & \\
\hline
\end{tabular}

Results are expressed as mean values \pm SEM

$* p<0.05, * * p<0.01$ and $* * * p<0.001$ vs control group

\# $p<0.05$ vs eucalyptol. ANOVA followed by Tukey's test

Table 3 Effect of eucalyptol on IL-1 $\beta$, TNF $\alpha$ and IFN- $\gamma$ levels

\begin{tabular}{|c|c|c|c|c|}
\hline \multirow[t]{2}{*}{ Treatment } & \multirow[t]{2}{*}{ Dose $(\mathrm{mg} / \mathrm{kg})$} & \multicolumn{3}{|l|}{$\begin{array}{l}\text { Cytokines } \\
(\rho g / m g)\end{array}$} \\
\hline & & $\mathrm{IL}-1 \beta$ & TNF- $\alpha$ & IFN- $\gamma$ \\
\hline Control (formalin) & - & $1.96 \pm 0.51$ & $117.80 \pm 24.78$ & $1.60 \pm 0.44$ \\
\hline Naive & - & $0.82 \pm 0.45$ & $28.42 \pm 8.73^{* *}$ & $0.04 \pm 0.04 * *$ \\
\hline Eucalyptol & 200 & $1.43 \pm 0.39$ & $58.82 \pm 12.44$ & $0.07 \pm 0.05^{* *}$ \\
\hline
\end{tabular}

Results are expressed as mean values \pm SEM

$* p<0.05$, ** $p<0.01$ and $* * * p<0.001$ vs control

\# $p<0.05$ vs eucalyptol. ANOVA followed by Bonferroni's test

cytokine release. Interestingly, IFN- $\gamma$ is known to activate innate responses by augmenting inflammatory cytokine and chemokine production, microbial killing and antigen presentation by mononuclear phagocytes such as macrophages (Hu and Ivashkiv 2009). Moreover, IL-12 produced by activated macrophages plays a central role in Th1 lymphocyte activation and can cause natural killer cells to release large amounts of IFN- $\gamma$ (Munder et al. 1998; Darwich et al. 2009). In our experiment, eucalyptol may have modulated IFN- $\gamma$-dependent proinflammatory mechanisms.

According to some authors, the anti-inflammatory effects of eucalyptol include the reduction of the expression of classic proinflammatory cytokines such as TNF- $\alpha$ and IL-1 $\beta$ in several models of inflammation (Santos et al. 2001; Juergens et al. 2004; Zhao et al. 2014; Kim et al. 2015). In a study by Santos et al. (2001), eucalyptol improved D-galactosamine/lipopolysaccharide-induced liver injury by reducing TNF- $\gamma$ levels. In addition, Kim et al. (2015) found that pretreatment with eucalyptol prevented lipopolysaccharide-induced lung injury. The authors also hypothesized that the anti-inflammatory effects of eucalyptol in acute lung inflammation may be mediated by a mechanism involving downregulated MMP9 expression and an extracellular signal-regulated kinasedependent NF-kB pathway. Interestingly, we observed no significant decrease in TNF- $\alpha$ and IL-1 $\beta$ levels in animals pretreated with eucalyptol. Ribeiro et al. (1997) suggested that mediators such as leukotriene B4 (LTB4) and complement component 5a can cause resident cells (such as mastocytes and macrophages) to release important mediators of neutrophil recruitment to the peritoneal cavity of mice. Eucalyptol may be involved in the direct stabilization of TNF- $\alpha$ and IL-1 $\beta$-stimulated target cells, thereby blocking IFN- $\gamma$ release. However, this hypothesis requires further testing.

The antinociceptive effect of eucalyptol $(200 \mathrm{mg} / \mathrm{Kg})$ was significantly inhibited by pretreatment with capsazepine (a competitive TRPV1 channel antagonist) but not ruthenium red (a noncompetitive TRPV1 antagonist) (Table 2), suggesting that eucalyptol interacts directly with a TRPV1 channel in the production of antinociception.

Regardless of dose, eucalyptol significantly decreased the time of capsaicin or glutamate-induced face rubbing and the number of eye wipes (induced by instillation of $5 \mathrm{M} \mathrm{NaCl}$ solution on the corneal surface) in relation to the control group (Table 4).

Capsaicin, a TRPV1 agonist, was used to investigate the mechanism involved in eucalyptol-induced antinociception. The observed inhibition of eucalyptol-induced antinociception by pretreatment with capsazepine along 
Table 4 Effect of eucalyptol on capsaicin- and glutamate-induced orofacial nociception and on hypertonic saline-induced corneal nociception

\begin{tabular}{|c|c|c|c|c|}
\hline \multirow[t]{3}{*}{ Treatment } & \multirow[t]{3}{*}{ Dose $(\mathrm{mg} / \mathrm{kg})$} & \multicolumn{3}{|l|}{ Rubbing } \\
\hline & & \multicolumn{2}{|l|}{ Face (s) } & \multirow{2}{*}{$\begin{array}{l}\text { Eyes }(n) \\
5 \mathrm{M} \mathrm{NaCl}\end{array}$} \\
\hline & & Capsaicin & Glutamate & \\
\hline Control & - & $33.83 \pm 7.05$ & $22.00 \pm 4.25$ & $12.20 \pm 0.66$ \\
\hline \multirow[t]{3}{*}{ Eucalyptol } & 100 & $8.50 \pm 2.05 * *$ & $7.00 \pm 1.39 * * *$ & $5.83 \pm 1.81^{*}$ \\
\hline & 200 & $1.17 \pm 0.60 * * * *$ & $4.50 \pm 2.15^{* * *}$ & $4.17 \pm 1.45^{* *}$ \\
\hline & 400 & $4.83 \pm 2.15 * * * *$ & $4.16 \pm 0.79 * * *$ & $3.83 \pm 1.17 * *$ \\
\hline
\end{tabular}

Results are expressed as mean values \pm SEM

$* p<0.05, * * p<0.01, * * * p<0.001$ and $* * * * p<0.0001 v s$ control. ANOVA followed by Tukey's test

\section{(A)}

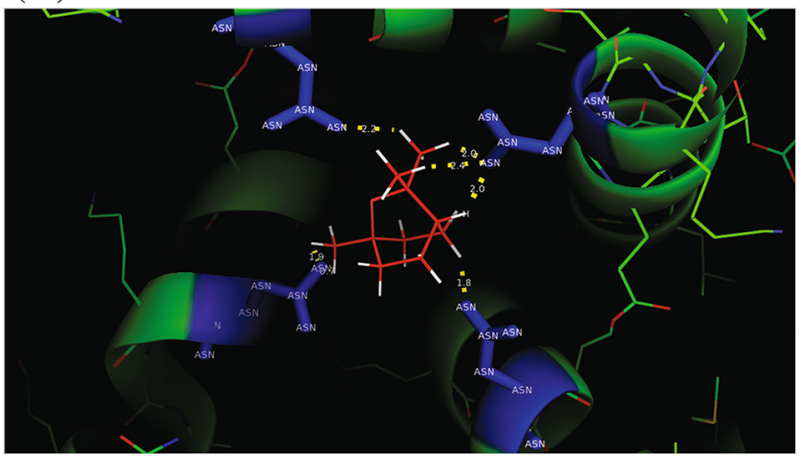

(B)

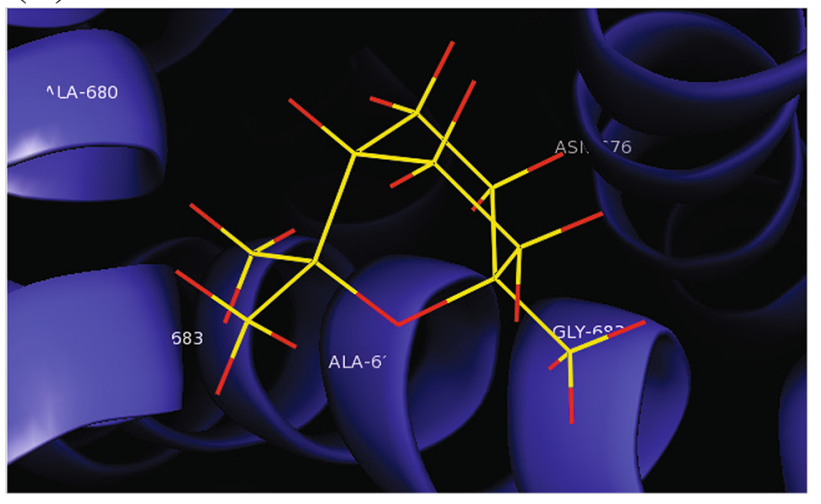

Fig. 2 Interaction between eucalyptol and TRPV1 (a) and amino acids (b)

with the observed antinociceptive effect of the model of capsaicin-induced nociception makes it possible to infer that eucalyptol is a vanilloid receptor antagonist.

Recent research has shown that the activation of NMDA receptors in the masseter muscle leads to TRPV1 sensitization, supporting the notion of a functional interaction between NMDA receptors and TRPV1 in the trigeminal ganglia (Ro et al. 2014). The fact that eucalyptol significantly prevented glutamate-induced nociception suggests antagonistic activity in the TRPV1 channel, leading to a decrease in glutamate release.
Due to its dense innervation and large population of TRPV1 receptors, the cornea is often used in studies on orofacial pain (Hegarty et al. 2014). Instillation of $5 \mathrm{M}$ $\mathrm{NaCl}$ induces corneal nociception and is considered a reliable model for the study of trigeminal nerve pain (Farazifard et al. 2005). The significant reduction in eye wipes observed in animals treated with eucalyptol reinforces the role of eucalyptol as a TRPV1 antagonist.

The results of the molecular docking study lend support to the notion of antagonistic activity in the TRPV1 channel by indicating a possible interaction between eucalyptol and TRPV1 receptors.

The direct action of eucalyptol on TRPV1 amino acids (Ala680, Gly683 and Asn 687; bond range 18-2.4 $\AA$ ) was viewed using PyMOL v1.4.7 (Fig. 2). The observed interaction, bond distance and high binding energy (Table 6) proves the relation between TRPV1 and the extremities of eucalyptol reactivity.

The injection of formalin or mustard oil into the TMJ induced nociceptive behaviors (head flinching and face rubbing). As shown in Table 5, treatment with eucalyptol at $200 \mathrm{mg} / \mathrm{kg}$ significantly reduced head flinching and face rubbing time.

TMJ disorders can cause persistent orofacial pain (Romero-Reyes and Uyanik 2014). The administration of TMJ irritants stimulates the afferent nociceptors, inducing nociceptive behaviors (Roveroni et al. 2001; Hartwig et al. 2003). The use of formalin and mustard oil in this study produced the expected characteristic behaviors (face rubbing and head flinching). Using these two models, we demonstrated the ability of eucalyptol to inhibit TMJ pain. Both irritants are considered TRPA1 agonists (Patapoutian et al. 2009), making it possible to infer that the orofacial antinociceptive effect of eucalyptol observed in these models is due to its role as a TRPA1 receptor antagonist.

Infraorbital nerve transection produced sustained changes in sensory processing, resulting in transient hypersensitivity to mechanical stimulation in the area innervated by the injured ION. Using this rodent model of facial neuropathic pain, our findings reveal that treatment 
Table 5 Effect of pretreatment with eucalyptol on formalin or mustard oil-induced nociception in the temporomandibular joint

\begin{tabular}{|c|c|c|c|c|c|}
\hline \multirow[t]{2}{*}{ Group } & \multirow[t]{2}{*}{ Dose (mg/Kg) } & \multicolumn{2}{|l|}{ Face rubbing (s) } & \multicolumn{2}{|l|}{ Head flinching (s) } \\
\hline & & Formalin & Mustard oil & Formalin & Mustard oil \\
\hline Control & - & $52.33 \pm 10.65$ & $39.83 \pm 17.77$ & $17.83 \pm 5.36$ & $9.83 \pm 1.01$ \\
\hline Eucalyptol & 200 & $5.60 \pm 1.47 * * *$ & $5.16 \pm 1.74 * *$ & $2.20 \pm 0.96^{*}$ & $2.83 \pm 1.49^{*}$ \\
\hline Sham & - & $6.83 \pm 1.74 * * *$ & $6.66 \pm 2.55^{*}$ & $2.00 \pm 1.41 * *$ & $1.50 \pm 0.61 * *$ \\
\hline
\end{tabular}

Results are expressed as mean values \pm SEM

$* p<0.05$ and $* * p<0.01 v s$ control. ANOVA followed by Tukey's test

Fig. 3 Antihyperalgesic effect of repeated eucalyptol treatment after the to infraorbital nerve transection. $* p<0.05$ and $* * p<0.01 v s$ control. ANOVA followed by the Bonferroni's test

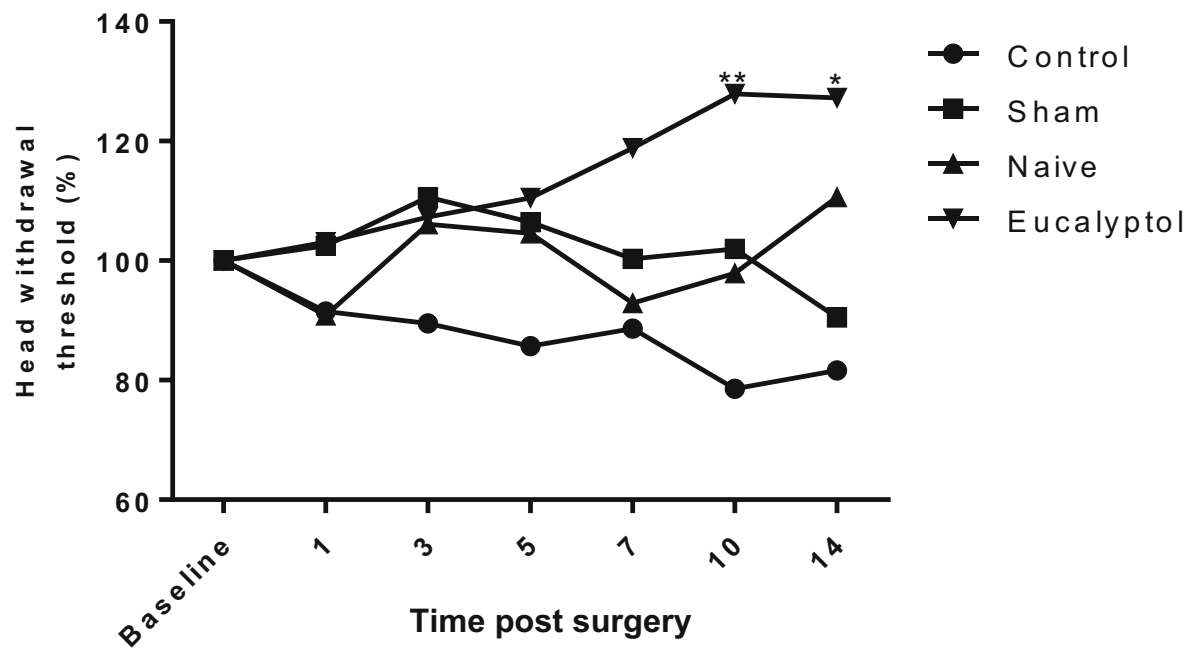

Table 6 Binding energies of the eucalyptol-TRPV1 complex

\begin{tabular}{ll}
\hline Cluster & Total E (Kcal/mol) \\
\hline 1 & -175.11 \\
2 & -172.72 \\
3 & -169.12 \\
4 & -166.53 \\
5 & -164.92 \\
6 & -164.88 \\
7 & -164.70 \\
8 & -163.95 \\
9 & -162.29 \\
10 & -161.19 \\
\hline
\end{tabular}

with eucalyptol can reduce mechanical-induced hypersensitivity (Fig. 3). This is an interesting finding since neuropathic pain in the orofacial region is the clinical manifestation of trigeminal nerve injury following oral surgeries such as tooth extraction, dental implantation or tooth pulp treatment (Iwata et al. 2011).

In the open-field test, no significant change in locomotor performance was observed between animals with and without eucalyptol treatment (data not shown), suggesting that eucalyptol has no unspecific muscle relaxation effect and supporting the findings of the nociception tests.

In conclusion, our study shows that eucalyptol may be a clinically relevant aid in the treatment of orofacial pain, possibly by acting as a TRPV1 channel antagonist.

Acknowledgements The authors would like to thank CNPq (310081/ 2011-4), Funcap (12535647-1) and Capes (053/14) for financial support, and Fundação Edson Queiroz for infrastructure.

\section{Compliance with ethical standards}

Conflict of interest The authors have no conflicts of interest to declare.

\section{References}

Anderson EM, Jenkins AC, Caudle RM, Neubert JK (2014) The effects of a co-application of menthol and capsaicin on nociceptive behaviors of the rat on the operant orofacial pain assessment device. PLoS One 9(2):1-9

Brito RG, Santos PL, Prado DS, Santana MT, Araújo AA, Bonjardim LR, Santos MR, de Lucca Júnior W, Oliveira AP, QuintansJúnior LJ (2013) Citronellol reduces orofacial nociceptive behaviour in mice-evidence of involvement of retrosplenial cortex and periaqueductal grey areas. Basic Clin Pharmacol Toxicol 112(4):215-221 
Caldas GF, Limeira MM, Araújo AV, Albuquerque GS, Silva-Neto JD, Silva TG, Costa-Silva JH, Menezes IR, Costa JG, Wanderley AG (2016) Repeated-doses and reproductive toxicity studies of the monoterpene 1,8-cineole (eucalyptol) in Wistar rats. Food Chem Toxicol 97:297-306

Chichorro JG, Lorenzetti BB, Zampronio AR (2004) Involvement of bradykinin, cytokines, sympathetic amines and prostaglandins in formalin-induced orofacial nociception in rats. Br J Pharmacol 141(7):1175-1184

Darwich L, Coma G, Peña R, Bellido R, Blanco E, Este J, Borras F, Clotet B, Ruiz L, Rosell A, Andreo F, Parkhouse M, Bofill M (2009) Secretion of interferon- $\gamma$ by human macrophages demonstrated at the single-cell level after costimulation with interleukin (IL)-12 plus IL-18. Immunology 126(3):386-393

de Sousa DP, Raphael E, Brocksom U, Brocksom TJ (2004) Antinociceptive profile of 2-phenylselenenyl-1,8-cineole in mice. Biol Pharm Bull 27(6):910-911

Farazifard R, Safarpour F, Sheibani V, Javan M (2005) Eye-wiping test: a sensitive animal model for acute trigeminal pain studies. Brain Res Brain Res Protoc 16(1-3):44-49

Guimarães AG, Silva FV, Xavier MA, Santos MR, Oliveira RC, Oliveira MG, Oliveira AP, de Souza CC, Quintans-Júnior LJ (2012) Orofacial analgesic-like activity of carvacrol in rodents. Z Naturforsch C 67(9-10):481-485

Guimarães AG, Serafini MR, Quintans-Júnior LJ (2014) Terpenes and derivatives as a new perspective for pain treatment: a patent review. Expert Opin Ther Patient 24(3):243-265

Hartwig AC, Mathias SI, Law AS, Gebhart GF (2003) Characterization and opioid modulation of inflammatory temporomandibular joint pain in the rat. J Oral Maxillofac Surg 61:1302-1309

Hegarty DM, Hermes SM, Largent-Milnes TM, Aicher AS (2014) Capsaicin-responsive corneal afferents do not contain TRPV1 at their central terminals in trigeminal nucleus caudalis in rats. J Chem Neuroanat 61-62:1-12

Hu X, Ivashkiv LB (2009) Cross-regulation of signaling pathways by interferon- $\gamma$ : implications for immune responses and autoimmune diseases. Immunity 31:539-550

Iwata K, Imamura Y, Honda K, Shinoda M (2011) Physiological mechanisms of neuropathic pain: the orofacial region. Int Rev Neurobiol 97:227-250

Juergens UR (2014) Anti-inflammatory properties of the monoterpene 1.8-cineole: current evidence for co-medication in inflammatory airway diseases. Drug Res (Stuttg) 64(12):638-646

Juergens UR, Engelen T, Racké K, Stöber M, Gillissen A, Vetter H (2004) Inhibitory activity of 1,8-cineol (eucalyptol) on cytokine production in cultured human lymphocytes and monocyte. Pulm Pharmacol Ther 17(5):281-287

Kim KY, Lee HS, Seol GH (2015) Eucalyptol suppresses matrix metalloproteinase-9 expression through an extracellular signalregulated kinase-dependent nuclear factor-kappa B pathway to exert anti-inflammatory effects in an acute lung inflammation model. J Pharm Pharmacol 67(8):1066-1074

Liapi C, Anifandis G, Chinou I, Kourounakis AP, Theodosopoulos S, Galanopoulou P (2007) Antinociceptive properties of 1,8Cineole and beta-pinene, from the essential oil of Eucalyptus camaldulensis leaves, in rodents. Planta Med 73(12):1247-1254
McNamara CR, Mandel-Brehm J, Bautista DM, Siemens J, Deranian KL, Zhao M, Hayward NJ, Chong JA, Julius D, Moran MM, Fanger CM (2007) TRPA1 mediates formalin-induced pain. Proc Natl Acad Sci USA 104(33):13525-13530

Mogil JS, Lichtensteiger CA, Wilson SG (1998) The effect of genotype on sensitivity to inflammatory nociception: characterization of resistant $(\mathrm{A} / \mathrm{J})$ and sensitive $(\mathrm{C} 57 \mathrm{BL} / 6 \mathrm{~J})$ inbred mouse strains. Pain 76(1-2):115-125

Munder M, Mallo M, Eichmann K, Modolell M (1998) Murine macrophages secrete interferon gamma upon combined stimulation with interleukin (IL)-12 and IL-18: a novel pathway of autocrine macrophage activation. J Exp Med 187:2103-2108

Patapoutian A, Tate S, Woolf CJ (2009) Transient receptor channels: targeting pain at the source. Nat Rev Drug Discov 8:55-60

Quintans-Júnior LJ, Melo MS, de Sousa DP, Araújo AA, Onofre AC, Gelain DP, Gonçalves JC, Araújo DA, Almeida JR, Bonjardim LR (2010) Antinociceptive effects of citronellal in formalin-, capsaicin-, and glutamate-induced orofacial nociception in rodents and its action on nerve excitability. J Orofac Pain 24(3):305-312

Ribeiro RA, Souza-Filho MV, Souza MH, Oliveira SH, Costa CH, Cunha FQ, Ferreira HS (1997) Role of resident mast cells and macrophages in the neutrophil migration induced by LTB4, fMLP and C5a des arg. Int Arch Allergy Immunol 112(1):27-35

Ro JY, Chung M-K, Lee JS, Saloman JL, Joseph L (2014) Functional interactions between glutamate receptors and TRPV1 in trigeminal sensory neurons. Mol Pain 10(Suppl. 1):O13

Rocha Caldas GF, Oliveira AR, Araújo AV, Lafayette SS, Albuquerque GS, Silva-Neto JC, Costa-Silva JH, Ferreira F, Costa JG, Wanderley AG (2015) Gastroprotective mechanisms of the Monoterpene 1,8-Cineole (Eucalyptol). PLoS One 5 10(8):e0134558 (1-17)

Romero-Reyes M, Uyanik JM (2014) Orofacial pain management: current perspectives. J Pain Res 7:99-115

Roveroni RC, Parada CA, Veiga MCFA, Tambeli CH (2001) Development of a behavioral model of TMJ pain in rats: the TMJ formalin test. Pain 94:185-191

Santos FA, Rao VS (2000) Antiinflammatory and antinociceptive effects of 1,8-cineole a terpenoid oxide present in many plant essential oils. Phytother Res 14(4):240-244

Santos FA, Silva RM, Tomé AR, Rao VS, Pompeu MM, Teixeira MJ, de Freitas LA, de Souza VL (2001) 1,8-cineole protects against liver failure in an in vivo murine model of endotoxemic shock. J Pharm Pharmacol 53(4):505-511

Sousa-Valente J, Andreou AP, Urban L, Nagy I (2014) Transient receptor potential ion channels in primary sensory neurons as targets for novel analgesics. Br J Pharmacol 171(10):2508-2527

Takaishi M, Fujita F, Uchida K, Yamamoto S, Sawada Shimizu M, Hatai Uotsu C, Shimizu M, Tominaga M (2012) 1,8-cineole, a TRPM8 agonist, is a novel natural antagonist of human TRPA1. Mol Pain 29(8):86

Zhao CH, Sun J, Fang CH, Tang F (2014) 1,8-Cineol attenuates LPSinduced acute pulmonary inflammation in mice. Inflammation 37(2):566-572 